\title{
Desain dan UJi Kinerja Mesin Pencacah Rumput Gajahtipe Reel
}

\author{
Design and Test Performance Of Cutter Machines Reel Type for Elephant Grass
}

\author{
Wahyu K Sugandi ${ }^{1}$, Asep Yusuf ${ }^{1)}$, Muhammad Saukat ${ }^{1)}$ \\ ${ }^{1)}$ Departemen Teknik Pertaniandan Biosistem, FTIP, Universitas Padjajaran \\ Jalan Raya Bandung-Sumedang Km 21, Jatinangor 40600 \\ Email : sugandiwahyu@gmail.com
}

\begin{abstract}
ABSTRAK
Kebutuhan rumput gajah untuk pakan ternak di daerah Lembang terus meningkat tetapi panjang potongan masih ada yang diatas 5 cmpadahal standar untuk silase (pakan ternak) mempunyai ukuran potongan rumput $1-5 \mathrm{~cm}$. Penelitian ini yaitu metode rekayasa dengan tahapan penelitian sebagai berikut: (1) Pengukuran karakteristik rumput gajah, (2) Analisis desain mesin pencacah rumput gajah yang meliputi desain silinder pisau pencacah, desain hoper, rangka dan sistem transmisi (3) Pembuatan prototipe mesin pencacah rumput gajah, (4) Uji fungsional mesin pencacah rumput gajah (5) Uji kinerja mesin pencacah rumput dan (6) Pengukuran panjang potongan rumput.Hasil penelitian menunjukkan bahwa rumput gajah memiliki rata - rata panjang daun $99,4 \mathrm{~cm}$, lebar daun 2,65 $\mathrm{cm}$, tebal daun $0,23 \mathrm{~cm}$, berat daun 7,8 gram. Mesin hasil rancangan memiliki dimensi panjang $800 \mathrm{~mm}$, lebar $750 \mathrm{~mm}$ dan tinggi $104 \mathrm{~mm}$. Daya yang dibutuhkan untuk mencacah rumput gajah adalah 1,6 kW dan kapasitas mesin adalah 1988 $\mathrm{kg} / \mathrm{jam}$. Panjang hasil pemotongan terhadap rumput gajah adalah $1-3 \mathrm{~cm}$.
\end{abstract}

Kata Kunci : Rumput Gajah, Uji Kinerja Mesin, Daya Pemotongan

\begin{abstract}
Demand with grass forage at Lembang has been increasing. But the quality did not yet to needs of cutting fodder where long pieces of shredded result there are more than $5 \mathrm{~cm}$. Therefore there was needs to be a studied of technology cutting of elephant grass in accordance with SNI standard. The purpose of this research was developed a machine capable of chopping grass with a precision cutting mechanism at the level of the required size $(1-5 \mathrm{~cm})$. The method used in this research was the method of engineering with research stages as follows: (1) Measurement characteristics of elephant grass, (2) design analysis elephant grass covering chopper blade cylinder design include design hoper, chassis and transmission systems (3) The built machine chopper (4) functional test machine (5)test performance machine and (6) length measurement Tests on engine design results showed that the physical characteristics of grass measurement results obtained the following data: average - the average length of $99.4 \mathrm{~cm}$ leaf, leaf width 2.65 $\mathrm{cm}, 0.23 \mathrm{~cm}$ thick leaves, leaf weight $7.8 \mathrm{grams}$. The dimensions of the machine were the length of $800 \mathrm{~mm}$, width $750 \mathrm{~mm}$ and height of 104. Power needed for chopped cane was $1.6 \mathrm{~kW}$ and machine capacity was $1988 \mathrm{~kg} / \mathrm{hr}$. The length of the grass cutting results was $1-3 \mathrm{~cm}$.
\end{abstract}

Keyword : Grass elephant, Test Performance Machine, Cutting Power

Diterima : 23 Juni 2016 ; Disetujui : 15 Agustus 2016 ; Online Published : 31 Oktober 2016

\section{PENDAHULUAN}

Hijauan Makanan Ternak (Forages) merupakan pakan utama ternak serta merupakan dasar dalam usaha pengembangan peternakan terutama untuk ternak ruminansia termasuk didalamnya sapi perah, sapi potong (pedaging). Untuk 
meningkatkan produktivitas ternak, salah satu faktor penting yang harus diperhatikan adalah penyediaan pakan hijauan sepanjang tahun baik kualitas dan kuantitas yang cukup agar pemenuhan kebutuhan zat-zat makanan ternak untuk mempertahankan kelestarian hidup dan keutuhan alat tubuh ternak (kebutuhan hidup pokok) dan tujuan produksi (kebutuhan produksi) dapat berkesinambungan. Hal ini dimungkinkan bila kita mampu mengelola strategi penyediaan pakan hijauan baik rumput maupun legum.

Indonesia, dengan kondisi iklim dan tanah yang subur, membuat peternak tidak pernah memikirkan dan merencanakan penyediaan pakan hijauan yang cukup baik kualitas maupun kuantitasnya. Sebagian besar peternak umumnya belum memiliki lahan yang cukup untuk budidaya hijauan, bahkan ada yang tidak memiliki lahan kebun rumput. Keterbatasan lahan untuk penanaman hijauan merupakan kendala bagi peternak. Disamping itu para peternak belum mengupayakan lahan kebun rumputnya dikelola secara baik dan efektif sehingga produktivitasnya belum optimal.

Produksi dari kebun rumput bila dipelihara secara optimum pada bulan basah akan menghasilkan hijauan yang maksimum, tetapi hasil ini perlu ditangani secara baik dan benar untuk dijadikan cadangan pada musim kemarau, sehingga dapat memenuhi kebutuhan hijauan untuk ternaknya baik secara kuantitas maupun kualitas. Hal ini dapat dilakukan jika sistem pengelolaan penyediaan hijauan dari pemotongan kemudian pencacahan dan diberikan langsung kepada ternak atau disimpan terlebih dahulu di gudang hijauan baru diberikan kepada ternak. Perubahan ini tidak mudah tetapi jika dicoba akan memberikan hasil yang efisien dan efektif dengan memfungsikan gudang pakan sebagai sentral manajemen pakan. Pada lingkup gudang pakan inilah perencanaan pakan peternak bermula, dari mulai panen hijauan hingga prosesing hijauan untuk persediaan dimusim sulit pakan. Salah satu sistem pengelolaan penyediaan hijauan adalah dengan cara pembuatan silase. Silase adalah pakan yang telah diawetkan yang diproduksi atau dibuat dari tanaman yang dicacah, pakan hijauan, limbah dari industri pertanian dan lain- lain dengan kandungan air pada tingkat tertentu yang diisikan dalam sebuah silo. Salah satu syarat dalam pembuatan silase adalah hijauan dalam hal ini adalah rumput gajah telah tercacah dengan baik dengan ukuran $1-5 \mathrm{~cm}$ setelah itu lalu dimasukkan kedalam silo yang dicampurkan dengan dedak dalam kondisi anaerob selama 21 hari untuk proses fermentasi.

Data yang diperoleh dari Perum Perhutani KPH Bandung Utara pada bulan Desember 2011 kebutuhan hijauan makanan ternak mencapai 600 ton/hari. Kebutuhan ini merupakan kebutuhan para peternak sapi yang tergabung dalam Koperasi Peternak Sapi Bandung Utara (KPSBU). Mengingat besarnya kuantitas rumput yang akan dicacah, kegiatan pencacahan hanya mungkin dilakukan dengan mekanisasi. Spesifikasi mesin pencacah juga harus memenuhi kebutuhan dan kondisi peternak sapi yang ada di Indonesia. Beberapa penelitian yang berhubungan dengan pencacahan seperti Mekanisme Pemotong Rumput Tipe Rotary (Suharyatun, 2002), Rancang Bangun Perajang Tembakau (Supriyadi, 2011), Alat Pencacah Kompos (Sudrajat,2006), Analisis Mekanisme Pemotongan Pelepah dan Tandan Sawit (Yazzid,2003) telah dilakukan tetapi penelitian yang khusus mengenai pencacah rumput gajah dengan menggunakan pisau tipe reel belum ada. Sehingga perlu dilakukan penelitian tentang teknologi pencacahan rumput gajah.

Penelitian ini bertujuan untuk merancang bangun dan mengkaji kinerja mesin pencacah rumput gajah yang meliputi desain mesin rancangan fungsional, rancangan struktual, kapasitas mesin, daya pemotongan, kecepatan putar (rpm) dan panjang hasil pemotongan. Sedangkan kegunaan dari penelitian ini diharapkan dapat mambantu para peternak terutama kualitas cacahan rumput gajah yang dibutuhkan oleh ternak.

\section{METODOLOGI PENELITIAN}

\section{Bahan dan Peralatan}

Bahan yang digunakan dalam penelitian ini adalah rumput gajah, benda kerja berupa besi siku, poros, plat, dan besi behel. Peralatan 
yang digunakan dalam penelitian ini adalah peralatan kerja bengkel, timbangan digital, timbangan gantung, stopwatch, tachometer, soundlevel meter, vibration meter, clampmeter, sabuk dan puli, bearing, oven dan motor listrik.

\section{Tahapan Penelitian}

Adapun Tahapan penelitian seperti yang disajikan pada Gambar 1.

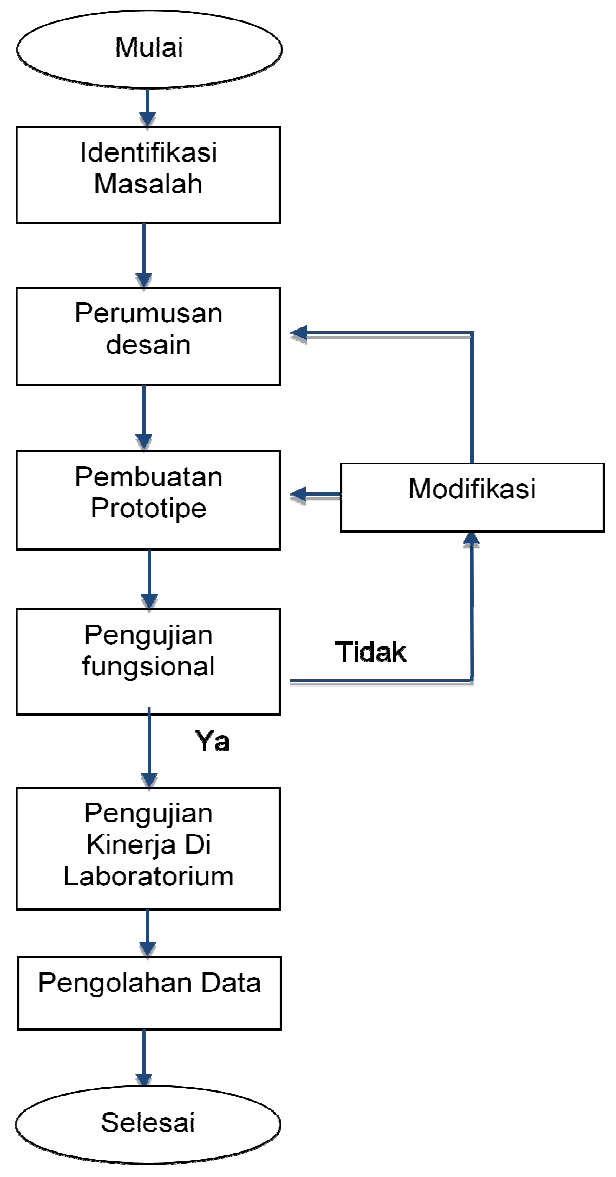

Gambar 1. Tahapan Penelitian

a. Identifikasi masalah. Permasalahan yang dihadapi oleh peternak sapi di daerah Lembang adalah masalah kualitas rumput gajah untuk pakan ternak. Hal ini disebabkan panjang potongan rumput gajah yang belum memenuhi standar SNI yaitu sekitar $1-5 \mathrm{~cm}$.

b. Perumusan disain. Berdasarkan masalah yang ada kemudian dirumuskan kriteria mesin pencacah yang sesuai dengan kebutuhan. Setelah kriteria perancangan ditetapkan kemudian proses perancangan yang dimulai dengan perancangan fungsional, bentuk dasar mesin dan melakukan analisa teknik untuk menentukan komponen - komponen mesin.

c. Pembuatan mesin. Pembuatan mesin dan uji kinerja dibuat di Bengkel Bahagia Jaya dan Laboratorium Alat dan Mesin Pertanian, FTIP, UNPAD.

d. Pengujian fungsional. Pengujian ini dilakukan untuk melihat apakah mesin dapat berfungsi atau melakukan tugas yang diinginkan atau tidak. Bila ya maka dilanjutkan pada uji kinerja mesin, bila tidak maka dilakukan modifikasi mesin.

e. Modifikasi. Hal ini dilakukan bila terdapat ketidaksesuaian antara rancangan funsional dengan operasional mesin pada saat dijalankan.

f. Uji Kinerja Mesin. Kegiatan ini dilakukan untuk mengetahui spesifikasi dari mesin itu sendiri. Seperti kapasitas, tingkat getaran mesin, tingkat kebisingan, daya pemotongan dan lain - lain.

\section{HASIL DAN PEMBAHASAN}

\section{Kriteria Rancangan}

1. Kapasitas Mesin pencacahan yang direncanakan adalah $300-500 \mathrm{~kg} / \mathrm{jam}$. Hal ini di dasarkan atas kebutuhan pakan ternak akan rumput gajah hingga mencapai 600 ton/bulan

2. Mekanisme Pemotongan menggunakan tipe reel mengingat sifat rumput gajah yang liat dan bulky.

3. Jumlah pisau yang dipasang pada reel adalah sebanyak 8 buah dengan harapan dapat memotong rumput gajah hingga panjang potongan $1-5 \mathrm{~cm}$.

\section{Proses Pencacahan Rumput Gajah}

Secara umum proses pencacahan (Gambar 2) dimulai dengan memasukkan rumput gajah kedalam hoper dengan cara didorong secara manual oleh tangan.

Silinder pencacah berputar searah jarum jam kemudian mengambil dan mencacah rumput gajah kedalam pisau pencacah yang akhirnya bahan dikeluarkan melalui unit pengeluaran sudah berbentuk potongan - potongan kecil. 
Pada bagian pencacah inilah diharapkan rumput gajah dapat memotong rumput gajah hingga panjang potongan $1-5 \mathrm{~cm}$.

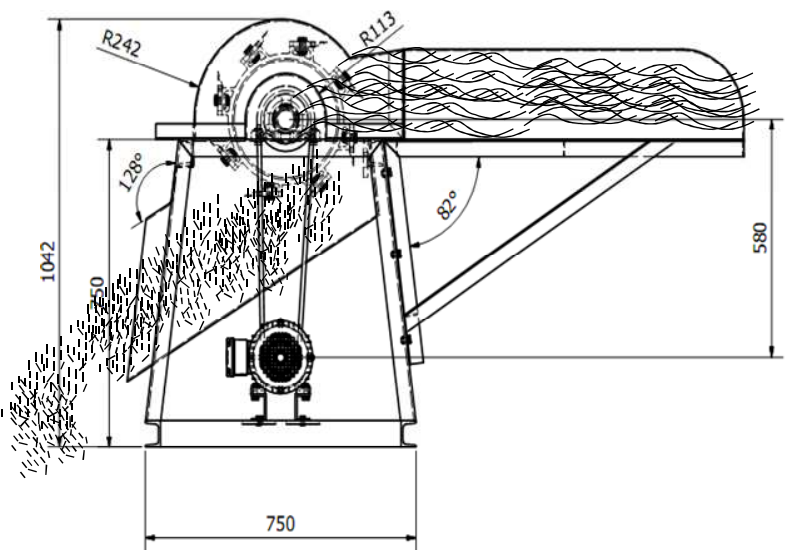

Gambar 2. Mekanisme Gerakan mesin

\section{Rancangan Fungsional}

Fungsi utama dari pencacahan rumput gajah adalah untuk mencacah rumput gajah sesuai kondisi rumput gajah dan panjang potongan yang diinginkan. Untuk memenuhi fungsi utama maka diperlukan fungsi penunjang yaitu mengumpankan rumput gajah untuk dicacah dan memotong rumput gajah yang diumpankan dengan panjang potongan yang dikehendaki. Pada fungsi pengumpanan diperlukan fungsi menjepit rumput gajah dan pengarah rumput gajah sehingga rumput gajah bisa masuk ke bagian silinder pencacah seperti yang disajikan pada Gambar 3 .

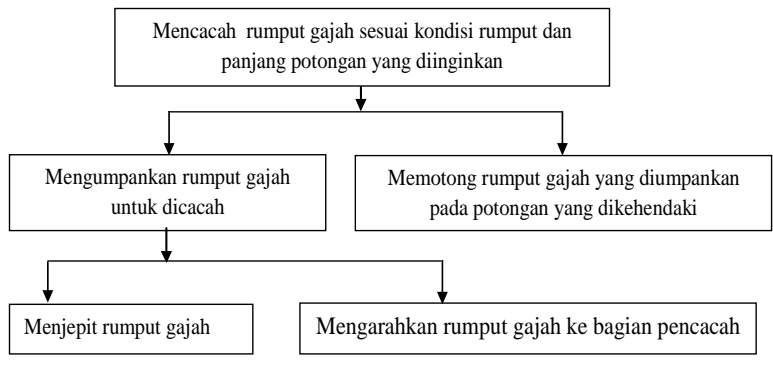

Gambar 3.Skema Rancangan Fungsional

\section{Desain dan Uji Kinerja Mesin Pencacah Rumput Gajah Untuk Pakan Ternak}

Hasil rancang bangun dan uji kinerja mesin pencacah rumput gajah untuk pakan ternak dengan menggunakan pisau tipe reel dibagi menjadi 4 bagian yaitu Rancangan Unit Pemasukkan Bahan, Rancangan Unit Pencacahan Bahan, Rancangan Sistim Transmisi dan Rancangan Unit Rangka Mesin. Setelah rancangan keempat unit mesin tersebut selesai maka kemudian digabung menjadi satu kesatuan mesin dengan harapan dapat menghasilkan cacahan rumput gajah dengan panjang potongan berkisar antara 1 $5 \mathrm{~cm}$

\section{Rancangan Unit Hoper}

Unit pemasukkan (hopper) merupakan bagian dari mesin pencacah yang berfungsi untuk memasukkan rumput gajah kedalam silinder pencacah. Pengumpanan rumput gajah dilakukan secara manual dengan arah horizontal. Adapun posisi operator adalah sebelah kanan mesin dengan tujuan agar tidak terkena percikkan hasil cacahan rumput gajah. Spesifikasi dari hopper adalah panjang 1000 $\mathrm{mm}$ lebar $400 \mathrm{~mm}$ dan tinggi $550 \mathrm{~mm}$ seperti yang disajikan pada Gambar 4

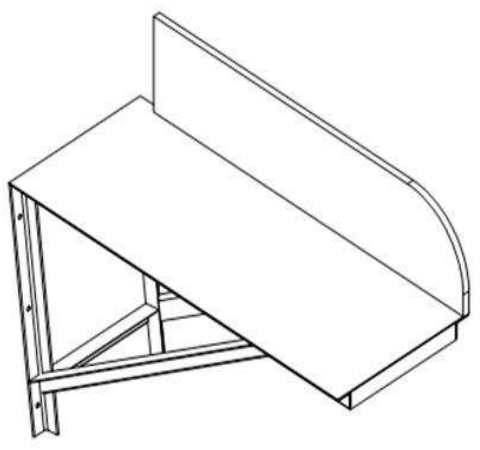

Gambar4. Desain Hopper

\section{Rancangan Unit Pencacah}

Pisau yang dipakai adalah pisau tipe reel yang ditempatkan pada dudukan pisau yang berbentuk silinder yang berfungsi sebagai pemotong rumput gajah.Tipe ini dipakai karena sifat rumput gajah yang liat dan bulkydengan harapan hasil potongannya bisa merata. Pada konstruksi silinder pencacah, pisau bergerak (movable blade) dipasang sebanyak 8 buah dan pisau diam (stasioner blade)dipasang sebanyak 1 buah. Bahan pisau terbuat dari bahan baja yang dikeraskan (heat treatment).Posisi pisau bergerak (movable) ditempatkan pada silinder berdiameter 320 $\mathrm{mm}$ dengan berat silinder $50 \mathrm{~kg}$. Untuk meneruskan sistem transmisi pada rangkaian 
unit pencacah perlu direncanakan diameter poros silinder sehingga sistem pengoperasian pencacahan dapat berjalan dengan baik. Berdasarkan hasil perhitungan diameter poros minimal silinder pencacah adalah $40 \mathrm{~mm}$. Untuk faktor keamanan maka diameter poros silinder yang dipakai adalah $45 \mathrm{~mm}$. Hal ini disesuaikan dengan ukuran yang ada di pasaran. Adapun rancangan diameter poros dan silinder pencacah seperti yang disajikan pada Gambar 5.

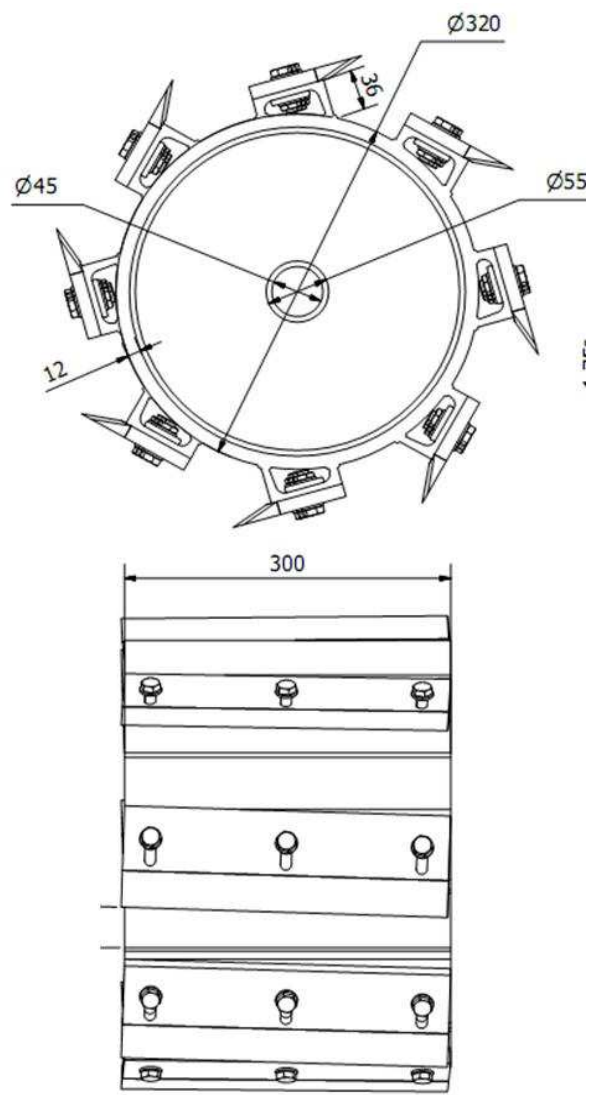

Gambar 5. Desain Pisau Pencacah

Posisi penempatan pisau pada silinder pemotong dibuat miring sekitar $3^{0}$ sehingga diharapkan dapat memotong (shear) rumput gajah menjadi ukurun kecil. Cara kerja dari pisau pencacah ini bergerak secara berputar kearah pisau diam (bedknife). Mengingat jenis pisau yang dipasang adalah pisau lurus maka ketinggian dudukan pisau antara ujung pisau dibuat tidak sama yaitu $15 \mathrm{~mm}$ dan $37 \mathrm{~mm}$. Hal ini dilakukan agar pada saat pemotongan berlangsung titik pisau dari ujung ke ujung dapat bertemu dengan pisau diam dengan jarak $1 \mathrm{~mm}$. Untuk kepentingan pengujian skala laboratoriun sumber putaran diambil dari motor listrik melalui poros pisau pencacah. Adapun bentuk pisau pencacah seperti terlihat pada Gambar 6 .

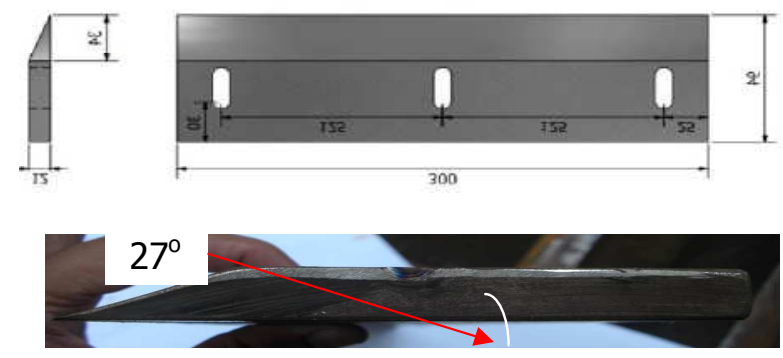

Gambar 6 Posisi Pisau.

Bentuk pisau dibuat panjang dengan sudut mata pisau adalah $27^{\circ}$, panjang pisau $30 \mathrm{~cm}$, lebar pisau $9.4 \mathrm{~cm}$, ketebalan pisau 1.2 $\mathrm{cm}$ dan berat pisau $1,5 \mathrm{~kg}$. Untuk mendapatkan panjang pemotongan $1 \mathrm{~cm}$ dengan kecepatan linier rumput gajah pada pengumpanan adalah1.4 $\mathrm{m} / \mathrm{s}$, jumlah pisau yang dipasang sebanyak 8 buah maka kecepatan putar yang dihasilkan adalah 1050 rpm.

\section{Analisis Rangka}

Rangka mesin berfungsi untuk menopang mesin pencacah rumput gajah secara keseluruhan. Pengukuran dimensi rangka sudah mempertimbangkan aspek ergonomi dan anthropometrik untuk kenyamanan operator. Adapun dimensi rangka mesin pencacah rumput gajah adalah panjang $800 \mathrm{~mm}$, lebar $750 \mathrm{~mm}$ dan tinggi $750 \mathrm{~mm}$ seperti yang disajikan pada Gambar 7. Bahan baku untuk pembuatan rangka adalah menggunakan besi siku dengan harapan bisa menopang mesin secara keseluruhan dan besi kanal dipasang di bawah rangka selain menahan getaran juga diharapkan dapat menahan beban terutama unit pencacah.

Bagian - bagian komponen tersebut kemudian di rakit dan disambungkan menggunakan mur baut, bantalan, puli dan belt. Hasil rakitan mesin pencacah rumput gajah dapat di bongkar pasang dengan tujuan mudah dalam perawatan bila terjadi kerusakan. Khusus untuk pisau pencacah secara berkala dapat dicopot dan diasah 
kembali sesuai kebutuhan.

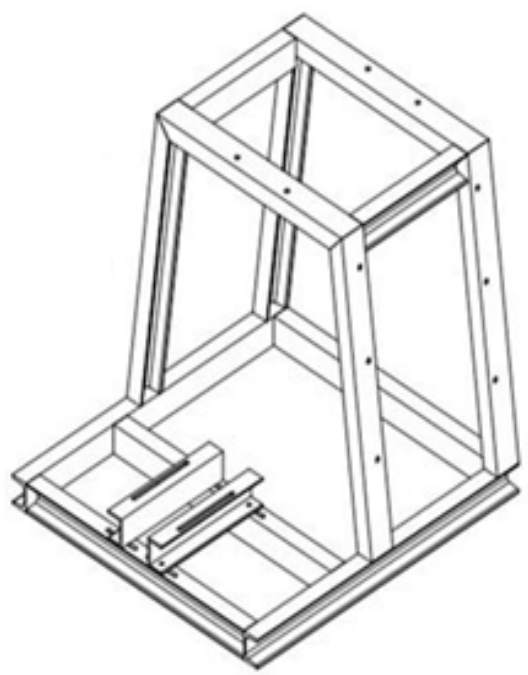

Gambar 7. Desain Rangka

Secara keseluruhan desain mesin pencacah rumput gajah bila digambar secara isometrik seperti yang dilihat pada Gambar 8 .

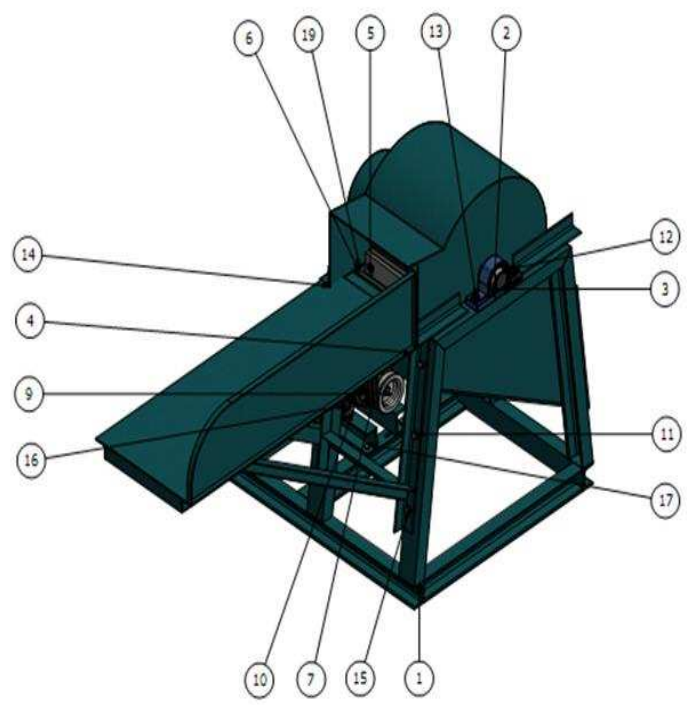

Gambar 8. Rancangan Konstruksi Mesin Pencacah Rumput Gajah

\section{Karakteristik Fisik Rumput Gajah}

Pengukuran karakteristik rumput gajah telah dilakukan di laboratorium Alat dan Mesin Pertanian, FTIP Unpad seperti yang disajikan pada Gambar 9.

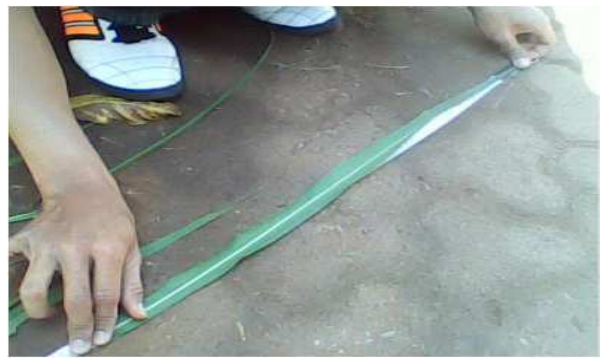

Gambar 9. Pengukuran Karakteristik Fisik Rumput Gajah

Dari hasil pengukuran terhadap rumput gajah diperoleh data - data seperti pada Tabel 1.

Tabel 1. Pengukuran Karakteristik Fisik Rumput Gajah

\begin{tabular}{lcc}
\hline \multicolumn{1}{c}{ Karakteristik } & $\begin{array}{c}\text { Rata - } \\
\text { rata }\end{array}$ & Kisaran \\
\hline Panjang daun $(\mathrm{cm})$ & 99,4 & $63-139,8$ \\
Lebar daun $(\mathrm{cm})$ & 2,65 & $1,4-4,8$ \\
Tebal daun $(\mathrm{cm})$ & 0,23 & 0,23 \\
Berat daun (gram) & 7,8 & $4,2-11,4$ \\
\hline
\end{tabular}

Dari data tersebut diperoleh rata - rata panjang daun adalah $99,4 \mathrm{~cm}$, lebar daun adalah $2,65 \mathrm{~cm}$, tebal daun adalah $0,23 \mathrm{~cm}$ dan berat daun adalah 7,8 gram. Data - data tersebut sangat diperlukan khususnya dalam mendesain mesin pencacah rumput gajah. tebal daun adalah $0.23 \mathrm{~cm}(2.3 \mathrm{~mm}$ ) maka jarak antara pisau pemotong rumput gajah tidak boleh lebih dari $2.3 \mathrm{~mm}$.

\section{Bulk Density Rumput Gajah}

Pengukuran kerapatan isi (bulk density) rumput gajah dilakukan di Laboratorium Alat dan Mesin Pertanian dengan bantuan bak kayu sebagai pengukur seperti yang disajikan pada Gambar 10.

Berdasarkan hasil pengukuran kerapatan isi rata-rata $157 \mathrm{~kg} / \mathrm{m}^{3}$. kerapatan isi akan sangat mempengaruhi mekanisme, pengaliran rumput gajah menuju bagian pencacah. Data tersebut juga bermanfaat untuk menentukan bentuk dan ukuran unit hoper dan unit pencacah serasah tebu. 


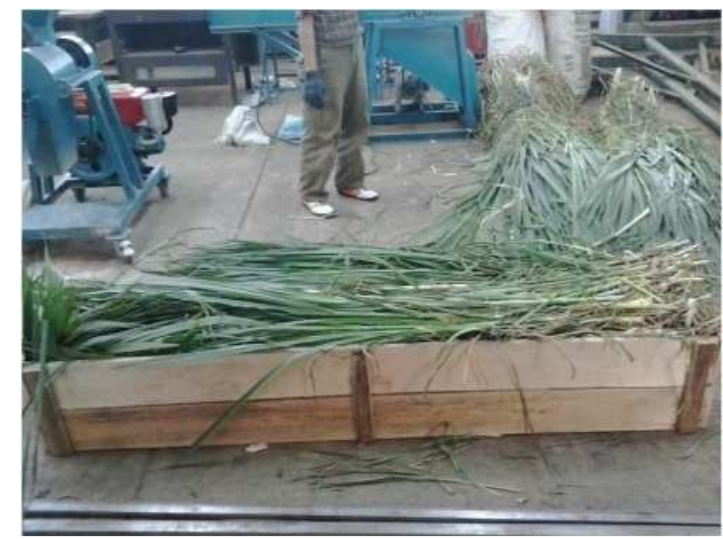

Gambar 10. Pengukuran Bulk Density

\section{Pembuatan Mesin Pencacah Rumput Gajah}

Secara keseluruhan proses pembuatan prototipe mesin pencacah serasah tebu didasarkan pada gambar kerja hasil rancangan. Adapun proses pembuatan dimulai dari pembuatan hoper, pembuatan rangka, silinder pencacah, sistim transmisi, dan lubang pengeluaran. Dengan mengikuti kaidah kaidah dalam mendisain suatu mesin, khususnya mesin - mesin pertanian pada akhirnya desain mesin pencacah rumput gajah dapat di pabrikasi. Secara struktural mesin pencacah rumput gajah dapat dilihat pada Gambar 11.

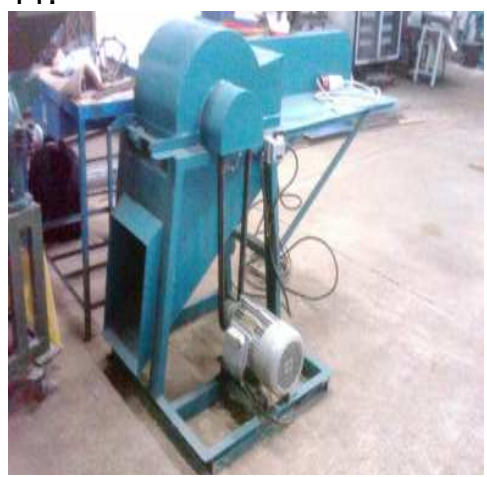

Gambar11. Prototipe Mesin Pencacah Rumput Gajah Dengan Menggunakan PisauTipe Reel

\section{Uji Kinerja Mesin Pencacah Rumput Gajah}

Uji kinerja secara stasioner (off farm) terhadap mesin pencacah rumput gajah telah dilakukan dengan bahan umpan adalah rumput gajah. Tujuan utama dalam uji kinerja ini adalah untuk mengetahui kemampuan mengalirkan bahan uji dalam hal ini adalah rumput gajah sekaligus mencacahnya menjadi potongan - potongan kecil (Gambar 12). Selain itu juga untuk mengetahui kapasitas aktual pada mesin tersebut dan hasil cacahannya.

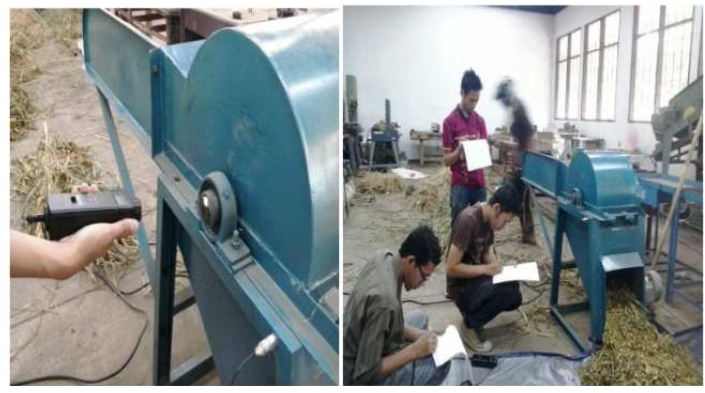

Gambar 12. Proses Pengujian Mesin

Pencacah Rumput Gajah

Berdasarkan hasil pengukuran kapasitas aktual mesin rumput gajah adalah $1988 \mathrm{~kg} / \mathrm{jam}$. Waktu yang diukur pada saat pengujian dimulai dari rumput gajah masuk hoper kemudian diteruskan pada bagian pencacah dan akhirnya keluar pada bagian pengeluaran. Tetapi panjang potongan dari rumput gajah masih jauh dari harapan lebih dari $4 \mathrm{~cm}$ dan hasil potongannya tidak seragam. Hal ini dikarenakan sudut pemotongan dari pisau pemotong tidak seragam, jarak antara pisau yang bergerak dengan pisau diam kurang rapat sekitar $1-2$ mm. Untuk mendapatkan hasil yang diharapkan telah dilakukan perbaikan khususnya pada sudut pemotongan yang telah diseragamkan sebesar $3^{\circ}$, lalu memperbaiki kerapatan antara pisau bergerak dengan pisau diam dengan jarak $0.5 \mathrm{~mm}$. Adapun untuk pengukuran daya pencacahan, kecepatan putar tingkat kebisingan dan tingkat getaran seperti yang disajikan pada Tabel 2 . Yang menjelaskan bahwa daya untuk mencacah rumput gajah adalah $1,4 \mathrm{~kW}$. Kecepatan putar menurun sekitar 942 rpm karena ada beban. Tingkat kebisingan dan tingkat getaran menaik ketika rumput gajah dimasukkan kedalam mesin pencacah rumput tetapi nilai tersebut masih dibawah ambang batas yang disarankan oleh KEPMENAKER yaitu $80 \mathrm{~dB}$. 
Tabel 2. Data Pengujian Mesin Pencacah Rumput Gajah

\begin{tabular}{|c|c|c|}
\hline Item Pengujian & $\begin{array}{l}\text { Beban } \\
\text { Kosong }\end{array}$ & Beban \\
\hline $\begin{array}{l}\text { Kapasitas Mesin } \\
\text { (Kg/jam) }\end{array}$ & - & 1988 \\
\hline $\begin{array}{l}\text { Daya } \quad \text { Mesin } \\
\text { Pencacah }(\mathrm{kW})\end{array}$ & 0,2 & 1,4 \\
\hline $\begin{array}{l}\text { Kecepatan Putar } \\
\text { (RPM) }\end{array}$ & 1003 & 942 \\
\hline $\begin{array}{l}\text { Tingkat Getaran } \\
(\mathrm{mm} / \mathrm{s})\end{array}$ & 3,35 & 18,23 \\
\hline $\begin{array}{l}\text { Tingkat } \\
\text { Kebisingan (dB) }\end{array}$ & 78,11 & 78,91 \\
\hline
\end{tabular}

\section{Hasil Potongan Rumput Gajah}

Jika dilihat secara keseluruhan terhadap hasil pemotongan rumput gajah. Maka terlihat bahwa pemotongan terhadap rumput gajah dengan menggunakan mesin pencacah rumput gajah tipe reel mendapatkan hasil potongan yang cukup rapih dan seragam. Adapun beberapa daun yang tidak tercacah disebabkan daun tersebut berbentuk pipih dan biasanya melilit pada silinder pencacah. Hasil cacahan rumput gajah pada mesin pencacah dapat dilihat pada Gambar 13

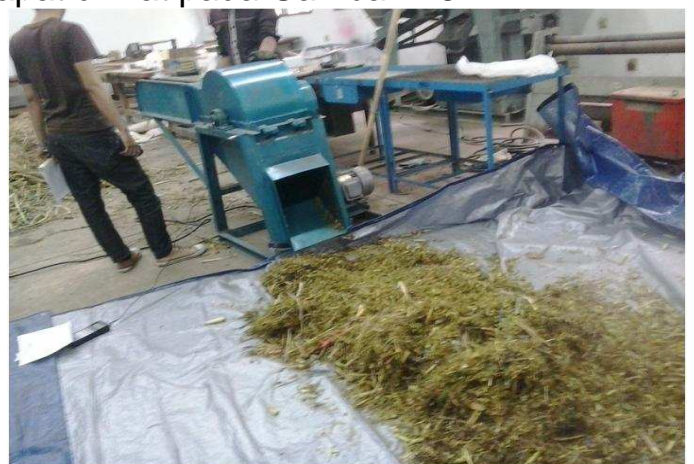

Gambar 13. Hasil Pemotongan Rumput Gajah

Adapun hasil pemotongan serasah setelah posisi pisau diperbaiki yaitu berkisar antara 1 - $3 \mathrm{~cm}$ mendekati perhitungan secara teoritis seperti yang terlihat pada Gambar 14 .

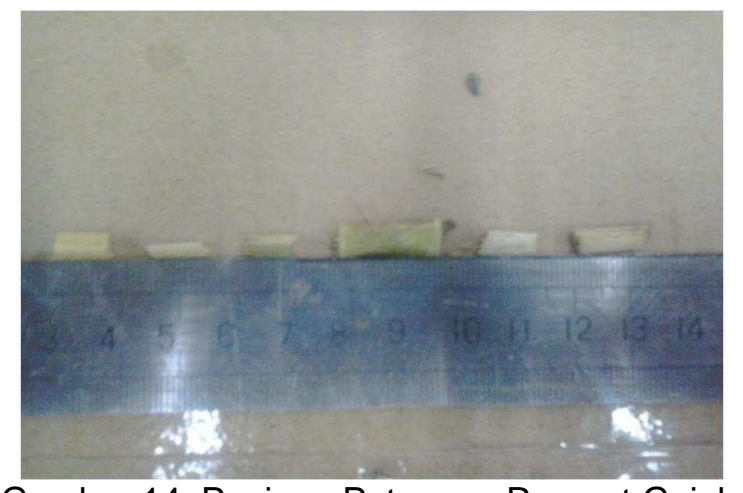

Gambar 14. Panjang Potongan Rumput Gajah

\section{KESIMPULAN DAN SARAN}

\section{Kesimpulan}

Karakteristik fisik dari rumput gajah hasil pengukuran diperoleh data sebagai berikut: rata - rata panjang daun $99,4 \mathrm{~cm}$, lebar daun $2,65 \mathrm{~cm}$, tebal daun $0,23 \mathrm{~cm}$, berat daun 7,8 gram. Kerapatan isi(bulk density) rumput gajahadalah $157 \mathrm{~kg} / \mathrm{m}^{3}$ dengan kadar air bahan $81,1 \%$. Dimensi mesin adalah panjang $800 \mathrm{~mm}$, lebar $750 \mathrm{~mm}$ dan tinggi 1042 . Jumlah pisau sebanyak 8 buah. Sistem transmisi menggunakan belt dan puli dengan ratio reduksi $1: 1,4$ dari motor penggerak ke unit pencacah. Kapasitas Mesin adalah 1988 $\mathrm{Kg} / \mathrm{jam}$. Daya yang dibutuhkan untuk mencacah serasah tebu adalah 1,6 kW. Tingkat getaran mesin $18,23 \mathrm{~mm} / \mathrm{s}$. Tingkat kebisingan mesin 78,11 dB. Panjang rata - rata pemotongan yang dihasilkan antara $1-3 . \mathrm{cm}$.

\section{Saran}

Untuk mendapatkan hasil potongan yang optimal disarankan untuk menggunakan pisau tipe helix. Perlu adanya tingkat clearance yang bisa diatur antara pisau diam (bed knife) dengan pisau bergerak .

\section{DAFTAR PUSTAKA}

Abbas.1996. Usaha Ternak Sapi. Kanisius. Yogyakarta

Anonimous. 2001. Pengawetan Hijauan Pakan Ternak (Silase). Proyek Peningkatan Sapi Perah Dirjen Peternakan - JICA Japan. Dinas Peternakan Jawa Barat 
Hunt, D. 1983. Farm Power and Machinery Managemet $8^{\text {th }}$ Ed. lowa State University Press Ames, lowa.

Khurmi, R.S. 2002. Strength of Materials. S Chand \& Company Ltd. Ram Nagar, New Delhi.

Persson, Sverker. 1987. Mechanics of Cutting Plant Material. An ASAE Monograph Number 7 in a series published by American Society of Agricultural Engineers. Michigan

Srivastava.1993 Engineering Prinsiple of Agricultural Machine.ASAE Textbook Number 6 Published by American Society of Agricultural Engineers.
Sitkey, G. 1986. Mechanics Of Agricultural Matrial. Elsevier, Amsterdam.

Sakai, RG Sitompul, E.Namaken, Radite PAS, N Suastawa. 1998. Traktor 2 - Roda. Laboratorium Alat dan Mesin Budidaya Pertanian. Jurusan Teknik Pertanian Fateta IPB Bogor.

Sudrajat. 2006. Mengelola Sampah Perkotaan. Penebar Swadaya. Jakarta

Suharyatun. 2002. Mekanisme Pemotong Rumput Tipe Rotary. (Tesis). Sekolah Pasca Sarjana IPB. Bogor

Supriyadi. 2011. Rancang Bangun Perajang Tembakau (Skripsi). Institut Teknologi Surabaya 